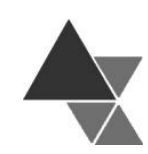

\title{
Atuação dos profissionais de saúde na investigação de suspeitas de surtos de DTA's nos hospitais de Uberlândia, Minas Gerais
}

\author{
Eliane Cristina Lombardi' ${ }^{1}$, Deborah Santesso Bonnas ${ }^{2}$, Fernanda Barbosa Borges \\ Jardim $^{3}$, Katiuce Aparecida de Oliveira ${ }^{4}$ Ricardo Tomaz da Silva ${ }^{5}$
}

Os programas de orientação de riscos à população contribuem para a redução de Doenças Transmitidas por Alimentos (DTA's). Quando há suspeita de surto de DTA's, os hospitais e unidades de saúde devem comunicar à Vigilância Epidemiológica Municipal para que o processo de investigação do surto tenha início. O objetivo do presente estudo foi identificar as falhas existentes no processo de investigação de surtos de DTA's em dois hospitais da rede privada e dois hospitais da rede pública de Uberlândia (Minas Gerais). Um total de 19 médicos pediatras ou clínicos gerais, que atendem casos de suspeita de surtos de DTA's, responderam dois questionários, sendo um de investigação e outro de pesquisa de opinião. Houve a sugestão de elaboração de uma ficha de DTA's de rápido preenchimento a ser utilizada durante o atendimento de casos suspeitos, com a descrição dos sintomas apresentados pelos pacientes no prontuário, local de ocorrência dos surtos e identificação do alimento consumido. O desenvolvimento de uma ficha própria por paciente e seu preenchimento compulsório pelos médicos facilitariam a inter-relação entre as vigilâncias municipais e o órgão de saúde. Estas medidas permitiriam maior eficácia nos processos de investigação de DTA's, visto que a interação entre os órgãos é deficiente, contribuindo para subnotificações de surtos de DTA's.

Palavras-chave: Vigilância Sanitária, Toxinfecções Alimentares, Saúde Pública.

\section{Performance of health professionals in the investigationof DTA's such in the Uberlândia hospitals}

The risk guidance program for the population, whether in residents, schools or public environments has contributed to the reduction of food-borne outbreak cases, and the reduction of drug and hospital stays costs as well. In the case of this type of outbreak, the hospital must communicate the city's Epidemiological Surveillance in order to start the investigation process. The objective of the present study was to identify the flaws in the procedures adopted during the DTA outbreaks investigations in hospitals, with the use of interviews with the

${ }^{1}$ Mestre em Tecnologia de Alimentos. Instituto Federal de Educação, Ciência e Tecnologia do Triângulo Mineiro, Uberaba, Minas Gerais. Endereço para correspondência: Av. Ortízio Borges nº 648, apto. 203 - Uberlândia (MG). Tel: (34)99123-9529. E-mail. elianecl@omail.com

${ }_{2}^{2}$ Doutora em Ciência dos Alimentos. Instituto Federal de Educação, Ciência e Tecnologia do Triângulo Mineiro, Uberaba, Minas Gerais. E-mail: deborahb@iftm.edu.br

${ }^{3}$ Doutora em Alimentos e Nutrição. Instituto Federal de Educação, Ciência e Tecnologia do Triângulo Mineiro, Uberaba, Minas Gerais. E-mailfernanda.jardim@ifftm.edu.br

${ }^{4}$ Mestre em Ciência e Tecnologia de Alimentos. Instituto Federal de Educação, Ciência e Tecnologia do Triângulo Mineiro, Uberaba, Minas Gerais. E-mail: katiuceapo@hotmail.com

${ }_{5}^{5}$ Doutor em Ciências Veterinárias. Universidade Federal de Uberlândia. E-mail. ricardovet@hotmail.com 
physicians who attended suspected DTA outbreaks in Uberlândia city's health network. The research project was approved by the Ethics Committee. Questionnaires were applied to physicians who attend in two private hospitals and in two Integrated Attending Units, according to a semi structured interview and an opinion survey form. The interviews with the doctors had the following results: suggestion to create a DTA fast filling form to be used during the care of DTA cases, description of the patient's symptoms in the medical report, suggestion of adding the outbreak place of occurrence and consumed food. The creation of this DTA form to be filled in public and private health units by physicians and the interrelation between the city health surveillance and health agencies are essential for a more effective outbreak investigation process, since the interaction between the organs is inefficient, which implies in the reduction of the reports of DTA outbreaks.

Keywords: Epidemiological Surveillance, Interviews, Hospital Stays.

\section{INTRODUÇÃO}

As Doenças Transmitidas por Alimentos (DTA's) são doenças relacionadas à ingestão de alimento ou água contaminada por microrganismos patogênicos, como as bactérias ${ }^{[1]}$. As DTA's são classificadas em três categorias: intoxicação alimentar, que é provocada pela ingestão de toxinas de microrganismos patogênicos pré-formadas nos alimentos; infecção alimentar, causada pela ingestão de células viáveis de microrganismos patogênicos invasivos, com habilidade de penetrar e invadir tecidos; e toxinfecções alimentares, que são causadas por microrganismos toxigênicos, que liberam toxinas quando estes se multiplicam, esporulam ou sofrem lise na luz intestinal[2].

A ocorrência de dois ou mais indivíduos com a mesma enfermidade após a ingestão de um mesmo alimento ou água é denominada de surto de DTA's ${ }^{[1]}$. Para tornar o processo de investigação de surtos de DTA's mais efetivo, os órgãos de vigilâncias sanitária e epidemiológica e as unidades de saúde devem trabalhar em conjunto, de maneira que as informações relatadas pelos pacientes durante as entrevistas, obtidas pela equipe de vigilância epidemiológica e no atendimento pelo médico, sejam compartilhadas para que as suspeitas de surtos sejam esclarecidas ${ }^{[3]}$.

Durante o atendimento dos pacientes em unidades de pronto atendimento, as informações e os dados do paciente são registrados em prontuários. As unidades de saúde públicas e privadas não dispõem de um formulário exclusivo para preenchimento no atendimento de pacientes com sintomas de DTA's[4].
A ficha preenchida pelas unidades de saúde para registro de sintomas de diarreia é a ficha de intoxicação exógena, disponibilizada pela Secretaria de Saúde do Estado. Essa ficha é preenchida pelos profissionais de enfermagem nas unidades de saúde e repassada para a vigilância epidemiológica municipal. O quadro de diarreia apresentado pelo paciente pode ser proveniente de diferentes tipos de enfermidades de origem alimentar, tais como: viral, intestinal, intestinal viral ou intestinal bacteriana, o que dificulta a conclusão de um diagnóstico, se não forem realizados, nos pacientes, exames específicos solicitados pelos médicos[5].

Geralmente, o diagnóstico clínico tem por base os sintomas da doença. É de grande importância para concluir o diagnóstico clínico, verificar a presença de indivíduos próximos com os mesmos sintomas e descobrir o tipo de microrganismo presente no alimento suspeito pela contaminação. Exames de coprocultura são um dos meios utilizados para a confirmação de um surto de origem alimentar. A investigação de um surto ocorre por suspeição epidemiológica, ou seja, quando todos os indícios indicam um alimento e os sintomas apresentados pelos pacientes são característicos de um agente etiológico[[].

Os pacientes que são acometidos por suspeitas de surtos de origem alimentar não costumam procurar com frequência, atendimento médico, pois os sintomas desaparecem num curto período. Esta conduta incorreta contribui para o aumento das subnotificações em municípios de diferentes regiões do país. Outro fator que contribui para o aumento das subnotificações é o registro das notificações, por parte das secretarias municipais de saúde, somente quando as doenças de origem alimentar atingem grande parte da população local[7]. 
Ação do profissional de saúde em surtos de DTA's em Uberlândia, Minas Gerais. Lombardi et al.

O objetivo deste estudo foi analisarirregularidades nos procedimentos adotados durante o processo de investigação de surtos de DTA's nos hospitais, por meio de entrevistas realizadas com médicos que atendem casos de suspeita de surtos de DTA's nas redes municipais e particulares de saúde em Uberlândia (Minas Gerais).

\section{CASUÍSTICA E MÉTODOS}

A pesquisa foi aprovada pelo Comitê de Ética da Universidade Federal do Triângulo Mineiro Uberaba - UFTM sob O CAAE61023216.0.0000.5154 sendo as informações de sigilo absoluto durante sua execução obedecendo aos princípios éticos estabelecidos pelo Conselho Nacional de Saúde (CNS), dispostos na Resolução 466 de $12 / 12 / 2012^{[8]}$. Todos os participantes e diretores clínicos das unidades foram esclarecidos quanto à sua participação no projeto e aos dados do projeto e assinaram $\mathrm{o}$ termo de consentimento livre $\mathrm{e}$ esclarecido.
Foram selecionados dois hospitais do setor público e dois hospitais do setor privado da cidade de Uberlândia, MG. Os participantes da pesquisa foram médicos clínicos gerais $(74 \%)$ ou pediatras $(26 \%)$, de ambos os sexos, vinculados profissionalmente aos hospitais selecionados, e envolvidos nos atendimentos ao público com sintomas suspeitos de surtos alimentares. Entre os meses de março a maio de 2017, foram entrevistados 19 médicos, sendo 10 (53\%) médicas na faixa etária entre 26 a 47 anos e nove (47\%) médicos na faixa etária entre 28 e 68.

O questionário de entrevista (Quadro 1) aplicado aos participantes foi semiestruturado e constava de questões objetivas e questões dissertativas sobre os procedimentos adotados pelos profissionais no atendimento de pacientes suspeitos de DTA's. O conteúdo abordado baseou-se em dados obtidos de fichas de investigação de surtos de DTA's, disponibilizada pela Secretaria de Vigilância em Saúde, por meio do SINAN (Sistema de Informação de Agravos de Notificação) [5].

Quadro 1.Roteiro de entrevista semi-estruturada aplicada a médicos que atendem pacientes suspeitos de DTA's em hospitais públicos e privados de Uberlândia, Minas Gerais

\begin{tabular}{|l|}
\hline Iniciais do nome e sobrenome: \\
\hline Data de nascimento: \\
\hline Sexo: ( ) Masculino( ) Feminino \\
\hline Órgão/Estabelecimento: \\
\hline Tempo de experiência profissional: \\
\hline Data da entrevista: \\
\hline Há registro das informações dadas pelo paciente acometido de doenças de origem alimentar ao médico? ( ) sim ( ) não \\
Se sim onde e como são registradas? \\
Sintomas que o paciente apresenta são registrados pelos médicos? ( ) sim ( ) não \\
Alimentos consumidos pelo paciente são registrados? ( ) sim ( ) não \\
Local onde o paciente se alimentou é registrado pelo médico? ( ) sim ( ) não \\
O hospital ou unidade básica de saúde passa alguma informação para a Vigilância Epidemiológica? ( ) sim ( ) não \\
Se sim quais e como essas informações são fornecidas? \\
Há uma ficha de informações referentes ao surto de doença de origem alimentar preenchida pelos profissionais de saúde?
\end{tabular}

Os participantes também responderam a um questionário de pesquisa de opinião composto por questões dissertativas (Quadro 2) para coleta de sugestões de dados que deveriam constar na ficha específica para surtos de DTA's nos hospitais. 
Ação do profissional de saúde em surtos de DTA's em Uberlândia, Minas Gerais. Lombardi et al.

Quadro 2. Pesquisa de Opinião aplicada aos médicos que atendem pacientes suspeitos de DTA's em hospitais públicos e privados de Uberlândia, Minas Gerais

\begin{tabular}{|l|}
\hline Iniciais do nome e sobrenome: \\
\hline Data de nascimento: \\
\hline Sexo: ( ) Masculino ( ) Feminino \\
\hline Órgão/Estabelecimento: \\
\hline Tempo de experiência profissional: \\
\hline Data da entrevista: \\
\hline A ficha atende as necessidades dos médicos de modo que facilite o trabalho do mesmo no processo de investigação do surto? \\
Qual informação deveria ser acrescentada na ficha? \\
Quais sugestões vocês têm a fazer para tornar o processo de investigação de surtos nas redes de saúde mais objetivo?
\end{tabular}

Os dados registrados nos questionários foram estratificados e tratados estatisticamente por meio da aplicação de estatística descritiva, preocupando-se em sintetizar e correlacionar o conjunto de dados obtidos nos questionários.

\section{RESULTADOS E DISCUSSÃO}

O percentual de médicos que detalharam, durante a entrevista, os procedimentos adotados pelos profissionais de saúde no diagnóstico e tratamento dos pacientes com suspeitas de surtos de origem alimentar foi de $32 \%$ (6) dos participantes. Os médicos, com tempo de profissão entre 8 a 42 anos $(8$ médicos)responderam na íntegra os questionários e forneceram informações mais completas, principalmente em relação ao diagnóstico e tratamento indicado aos doentes. $O$ tempo de experiência profissional dos médicos entrevistados no município de Uberlândia variou de 8 meses a 42 anos. Dos médicos (as) que aceitaram participar da pesquisa, 58\% (11) tinham até seis anos de experiência na profissão.

Em caso similar ao encontrado neste estudo, identificou-se, por meio de uma pesquisa realizada em sete hospitais no Distrito Federal, que 28,5\% dos profissionais de saúde tinham de 0 a 5 anos de profissão[ ${ }^{[3]}$.

Quanto ao questionamento se há registro das informações disponibilizadas pelo paciente acometido de enfermidades de origem alimentar ao médico, 16 médicos (84\%) entrevistados responderam que realizam o registro dessas informações e que as informações fornecidas pelos pacientes são registradas em um prontuário eletrônico ou ficha do paciente, sendo os sinais e sintomas verificados no exame físico realizado no momento da consulta.

O registro dos sintomas apresentados pelos pacientes em prontuário, pelo médico, é importante para que o hospital tenha as informações dos pacientes cadastradas no sistema, como forma de melhorar a busca ativa dos procedimentos realizados com os pacientes, tais como consultas e exames médicos e facilitaria na elaboração de um diagnóstico e também no tratamento da doença.

O prontuário é um documento de registro de informações das patologias de importância para médicos, pacientes e equipe de saúde. Para o paciente, os dados lançados no prontuário permitem $\mathrm{O}$ atendimento, o diagnóstico e o tratamento da doença com maior agilidade e eficiência. Para os médicos, um prontuário bem planejado é considerado um documento de aplicabilidade no diagnóstico e tratamento das doenças e no fornecimento de um laudo mais seguro. Para a equipe de saúde, o prontuário possui a função de intercomunicação, uma vez que apresenta as informações relacionadas a cada especialidade, na qual o paciente foi atendido ${ }^{[4]}$.

Em estudo realizado em Brasília foi verificado que a busca ativa nos prontuários e nos boletins de atendimento dos pacientes era realizada diariamente, por meio dos sistemas de informações e os atendimentos realizados no período noturno eram avaliados no dia subsequente. Em alguns hospitais, era realizada busca ativa de resultados de exames laboratoriais de alguns casos suspeitos ${ }^{[3]}$.

Nos Estados Unidos, os sistemas de relatórios formais representam um papel importante 
na detecção dos surtos, por médicos e microbiologistas. Cada estado tem o dever de mencionar as doenças de origem alimentar e como diagnosticá-las nos pacientes, a partir de uma lista de doenças obrigatórias (que engloba as DTA's). Pela análise dos dados contidos nos relatórios, se os profissionais de saúde observarem incidência elevada de casos de uma determinada doença, o Departamento de Saúde é acionado e os casos são discutidos. Quando o médico suspeita que o paciente apresenta sintomas de DTA's, ele pode solicitar ao paciente que faça a coleta de uma amostra de fezes para exames em laboratório. O laudo do exame permite ao médico traçar o quadro clínico do paciente e tratar adequadamente a doença[ [] . De acordo com as respostas obtidas nas entrevistas realizadas com 12 $(63 \%)$ médicos, verificou-se que os hospitais não fazem o procedimento de coleta de amostras de fezes para análise e, na maioria das vezes, os indivíduos procuram atendimento médico quando já não apresentam os sintomas de DTA's ${ }^{[0]}$.

Quanto ao questionamento se há registro, pelos médicos, dos sintomas apresentados pelo paciente no prontuário, os 19 médicos (100\%) participantes da entrevista afirmaram que sim. O registro destas informações nos prontuários é importante, pois permite aos profissionais de saúde elaborar um diagnóstico clínico mais adequado da doença e fazer a prescrição de um tratamento eficiente. Os sintomas relatados pelos pacientes são os principais dados para que os médicos possam diagnosticar o agente etiológico causador da DTA.

Quanto ao questionamento se há registro dos alimentos consumidos pelo paciente, 13 médicos $(68 \%)$ entrevistados responderam afirmativamente. Geralmente alguns médicos não fazem o registro dos alimentos consumidos, no caso de os indivíduos acometidos pelo surto não conseguirem identificar todos os alimentos consumidos no dia da ocorrência do surto de DTA. A detecção do alimento provável causador do surto poderia ser importante para que a equipe de Vigilância Sanitária do Setor de Alimentos implementasse orientações aos estabelecimentos sobre a conservação adequada de determinados alimentos que apresentam maior incidência de causar surtos de origem alimentar.

O registro dos alimentos consumidos, no prontuário do paciente, reallizado nas unidades de saúde contribui no processo de investigação de suspeitas de surtos de origem alimentar de forma a obter, em um menor intervalo de tempo, informações relevantes para a conclusão do surto. Esta ação também possibilita agrupar informações de dados semelhantes disponibilizadas pela vigilância epidemiológica e a rede de saúde, com intuito de reduzir a incidência de surtos inconclusivos.

Em Brasilia, os registros de detecção e notificação de eventos, tais como, surtos de DTA ocorridos em locais de grandes aglomerações, como festas, reunião, importantes para a saúde pública podem ser feitos pelo telefone, computadores com acesso à internet e correio eletrônico. Os equipamentos são disponibilizados nas salas do núcleo hospitalar, nas quais os médicos $(28 \%)$ têm acesso, para uso durante o período de trabalho[3].

Em Uberlândia(MG) os registros e as notificações de surtos de DTA podem ser feitas pelo telefone, por meio de reclamações feitas pelos contribuintes que podem ser direcionadas tanto para o Setor de Vigilância Sanitária quanto ao Setor de Vigilância Epidemiológica ou pessoalmente no Setor de Protocolo da Vigilância Sanitária do município.

Apenas quatro (21\%) médicos participantes responderam afirmativamente ao questionamento se há o registro do local onde o paciente se alimentou. Devido não ter esse questionamento no prontuário preenchido pelo médico e o atendimento em pronto socorro ter que ser rápido, algumas informações importantes na detecção do surto não são registradas e também por não ter uma ficha de preenchimento específico no caso de DTA's. O registro do local de ocorrência da suspeita de surtos de origem alimentar no prontuário é importante, pois colabora com os procedimentos de investigação de surtos realizados pela vigilância sanitária municipal e permite à equipe técnica de fiscais verificar as condições higiênicossanitárias do local, bem como a estrutura física e os procedimentos adotados na manipulação de alimentos.

Quanto ao questionamento se as informações de ocorrência de surtos de origem alimentar são fornecidas ao setor de vigilância epidemiológica, seis $(32 \%)$ médicos entrevistados não sabiam dizer se existe este procedimento, cinco $(26 \%)$ responderam 
afirmativamente e oito $(42 \%)$ médicos disseram que as informações não são repassadas.

Quando as informações de ocorrência de surtos de doenças transmitidas por alimentos registradas nos hospitais, principalmente no pronto socorro, não são fornecidas para o setor de Vigilância Epidemiológica, o registro de casos de DTA's na Secretaria de Saúde do município é inviabilizado. Consequentemente, há um aumento de subnotificações dos surtos.

Os casos de surtos de DTA's devem ser comunicados a vigilância sanitária por meio do sistema de informação de agravos e notificações (SINAN), por meio de preenchimento de formulário próprio. Este processo é ineficiente, pois a maioria dos médicos não tem conhecimento que deve ser realizada tal notificação.

A notificação da ocorrência de surtos de DTA's é realizada por meio do SINAN. A população tem o compromisso de informar à autoridade sanitária sobre a ocorrência de um surto de enfermidades de origem alimentar, assim como os profissionais de saúde, médicos e dirigentes de estabelecimentos públicos e particulares de saúde. Porém, tais ações não são realizadas, pois a maioria da população não tem conhecimento da existência deste procedimento de notificação. Os órgãos responsáveis não realizam ações educativas abordando a existência do sistema à população[10].

No Brasil, a Agência em Vigilância Epidemiológica de doenças transmitidas por alimentos (VE-DTA) tem como principais objetivos detectar, controlar e prevenir surtos de doenças veiculadas por alimentos, identificando sempre que possível, o agente etiológico envolvido e o desenvolvimento de medidas de controle e prevenção para as mesmas. Além desses objetivos, também é papel da vigilância epidemiológica, a capacitação de equipes em vigilância em saúde ${ }^{[11]}$. Em Uberlândia, a equipe de vigilância em saúde não possui sistema de capacitação regular. Este tipo de capacitação é realizado somente pela vigilância sanitária estadual e não é constante.

Em estudo de caso realizado em Brasília, sobre a capacidade de resposta da rede hospitalar de emergência a eventos associados a viajantes internacionais, identificou-se que um dos três hospitais entrevistados possui um Núcleo de Vigilância Hospitalar de Epidemiologia, que é responsável pela notificação, registro no SINAN e manutenção das fichas de agravos, doenças e eventos detectados no hospital[3].

Nos Estados Unidos, a agência responsável pela vigilância epidemiológica é o Centro de Controle e Prevenção de Doenças (CDC), criado em julho de 1946, e que inicialmente tinha como objetivo o combate à malária. $\mathrm{O} \mathrm{CDC}$ possui como principais diretrizes a vigilância em saúde para monitorar e prevenir surtos de doenças, projetar e promover políticas de saúde pública, implementar estratégias de prevenção e realizar estudos que garantam a melhoria da qualidade de vida da população[?]. Para tornar a notificação dos surtos de DTA's mais eficaz, deveria ser criado um órgão específico dentro dos hospitais que fizesse com maior agilidade a comunicação dos surtos de DTA's para a vigilância epidemiológica[ ${ }^{[1]}$.

Quanto à existência de ficha de informações referentes ao surto de DTA's preenchida pelos profissionais de saúde, oito (42\%) dos médicos entrevistados disseram que não há uma ficha de registro para os médicos preencherem relacionada a suspeita de surtos de DTA's e seis $(32 \%)$ dos médicos disseram desconhecer essa informação. Um total de 5 $(26 \%)$ médicos apresentaram resposta afirmativa, porém a ficha que os médicos relatam ser de notificação de DTA's são as fichas de intoxicação exógena (preenchida no pronto socorro) que devem ser preenchidas quando há um único paciente que apresentou sintomas de DTA's. Ou seja, os médicos apresentaram dúvidas sobre o processo de investigação de surtos de DTA's e sobre a importância da sua participação nesse processo que consiste em coletar informações relevantes, tais como, registros dos alimentos consumidos, local de ocorrência do surto e sintomas apresentados durante o atendimento.

$\mathrm{Na}$ entrevista de pesquisa de opinião, os participantes foram questionados se haveria a necessidade da criação de uma nova ficha que facilite o trabalho dos médicos no processo de investigação de surtos. Todos os entrevistados confundiram esta ficha (que se propôs a se desenvolver) com a ficha disponibilizada pelo SINAN, quando há dois casos ou mais de doenças de origem alimentar (em caso de surtos). Além disso, relataram a necessidade de treinamento e orientação nos hospitais e redes de 
Ação do profissional de saúde em surtos de DTA's em Uberlândia, Minas Gerais. Lombardi et al.

saúde quanto ao registro de casos de DTA's. Os médicos apresentaram dúvidas sobre o procedimento de investigação de surtos, uma vez que oito (42\%) médicos não souberam responder se uma ficha para registro de surtos de DTA's é preenchida nas redes de saúde.

Um estudo similar, em três hospitais de Brasilia, constatou que do total de 67 médicos entrevistados, $39(58,2 \%)$ afirmaram desconhecer o fluxo de notificação de surtos de DTA's entre as diferentes equipes dentro dos hospitais. Dentre os 28 médicos $(41,8 \%)$ que relataram conhecer o fluxo, 19 $(70,4 \%)$ detalharam esta ação quando solicitados. Dos 19 profissionais que descreveram o fluxo de notificação, apenas $2(10,5 \%)$ o descreveram de forma correta do ponto de vista das instâncias envolvidas 12 $(63,7 \%)$ disseram que a responsabilidade de notificação é do Núcleo de Vigilância Hospitalar e 5 (26\%) detalharam os métodos de notificação: o médico deve informar a ocorrência do surto de DTA's para a chefia da enfermagem; a notificação de surto de DTA's deve ser encaminhada para a chefia da equipe de enfermagem e após para o Núcleo de Vigilância Hospitalar e que a notificação de surto de DTA’s após ser realizada pelo Núcleo de Vigilância Hospitalar, teria que ser confirmada por exame laboratorial para posteriormente ser digitada no SINAN[3].

A capacitação dos médicos é importante, pois os mesmos devem ter conhecimento da importância do fluxo de informações para os outros setores e a importância da transmissão na elucidação destes surtos.

Quanto ao questionamento se deveria ser acrescentada alguma informação na ficha, os médicos sugeriram que fosse acrescentado o local de ingestão dos alimentos, tipo de alimentos consumidos, data do consumo do alimento e os sintomas básicos para facilitar o protocolo de um tipo de tratamento. A maioria dos médicos (84\%) afirmou que o desenvolvimento de uma ficha de surtos de DTA's de rápido preenchimento seria necessário, pois durante $\mathrm{o}$ atendimento seria inviável o preenchimento de uma ficha extensa devido ao fluxo intenso de pacientes doentes no pronto atendimento das redes de saúde.

Quanto ao questionamento se os médicos teriam sugestões para tornar o processo de investigação de surtos nas redes de saúde mais objetivo, 16 médicos (84\%) apresentaram as seguintes sugestões: maior interação entre os serviços de vigilância com a unidade de pronto atendimento; elaboração de uma ficha para ser utilizada pelos médicos no atendimento de pacientes com suspeita de doenças de origem alimentar; melhora no fluxo de informações entre a equipe de médicos e a equipe de enfermagem para que as notificações de suspeitas de surtos de origem alimentar sejam registradas nas unidades de saúde; treinamento e disponibilização de um técnico de enfermagem específico para atuar nesse tipo de registro; formulação de uma ficha eletrônica não muito extensa, objetiva, de fácil preenchimento e que tenha como identificar o alimento consumido e o local de consumo; criação de um prontuário com a origem dos sintomas específicos para doenças transmitidas por alimentos, pois as sintomatologias são similares em comparação com diversos tipos de doença como enfermidades de origem alimentar e outras viroses; criação de um programa hospitalar interno de investigação de suspeitas de surtos.

Uma ficha foi sugerida e elaborada por um dos médicos entrevistados durante a pesquisa (Quadro 3). 
Quadro 3. Modelo de Ficha de DTA's sugerida por um médico durante as entrevistas realizadas com os profissionais de saúde em dois hospitais particulares e em duas unidades de atendimento integrados no município de Uberlândia, Minas Gerais

\begin{tabular}{|c|c|c|c|c|}
\hline \multicolumn{5}{|c|}{ Dados Pessoais } \\
\hline \multicolumn{5}{|l|}{ Nome: } \\
\hline Data de Nascimento: & \multirow{2}{*}{\multicolumn{4}{|c|}{ 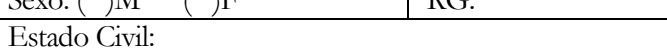 }} \\
\hline CPF: & & & & \\
\hline Infecção Viral & & & & \\
\hline Infecção Intestinal & & & & \\
\hline Infecção Indeterminada & & & & \\
\hline Infecção Intestinal Viral & & & & \\
\hline Infecção Intestinal Bacteriana & & & & \\
\hline Registro de Dados & $\operatorname{Sim}$ & Não & & Qual \\
\hline \multicolumn{5}{|l|}{ Agente Etiológico } \\
\hline \multicolumn{5}{|l|}{ Identificação do Alimento } \\
\hline Local do Surto & & & & \\
\hline
\end{tabular}

A ficha proposta (Quadro 3) permite, de forma simples e eficiente, identificar se o tipo de doença que o paciente apresenta tem relação com os surtos de origem alimentar e otimiza o trabalho dos médicos do pronto atendimento.

Foi possível identificar que o processo de investigação de suspeita de surto de origem alimentar nas unidades de saúde apresenta algumas falhas. As unidades integradas de saúde e os hospitais particulares que participaram da entrevista não possuem uma ficha padrão para preenchimento, no caso de atendimento de pacientes com sintomas relacionados à DTA's. Os sintomas apresentados pelos pacientes são registrados em formulário eletrônico ou redigidos na ficha do paciente, portanto não é disponibilizada aos médicos uma ficha de suspeitas de surtos de origem alimentar própria da unidade de saúde. Este quadro implica em dificuldades no diagnóstico de DTA's, e no tratamento das doenças. Consequentemente, a notificação é ausente ou ineficaz.

De acordo com os médicos entrevistados, os sintomas relacionados com as enfermidades de origem alimentar são parecidos com outras diversas doenças, tais, como, diarreia viral e viroses em geral.

O estudo indicou que os métodos de identificação dos surtos de DTA's, como a coleta de amostras para exames laboratoriais, não são realizados pelos profissionais de saúde, principalmente nas unidades básicas e integradas de saúde da rede pública. De acordo com as respostas dadas pelos médicos aos questionários dos Quadros 1 e 2, os motivos citados nas fichas que seriam causadores dessas falhas são que os pacientes acometidos por surtos de DTA's não comunicam aos órgãos responsáveis pela investigação em tempo hábil e as redes públicas não possuem um programa de coletas de amostras que possa contribuir na detecção de DTA's. São pertinentes maior envolvimento e cuidados das unidades de saúde, vigilâncias sanitárias e epidemiológicas, e de seus representantes, na investigação dos surtos de DTA's, permitindo que o atendimento ao público seja de melhor qualidade.

Uma oportunidade de melhoria apontada pela pesquisa por $12(58 \%)$ médicos foi a necessidade de treinamento ou de orientação aos profissionais de saúde sobre o processo de investigação de surtos de origem alimentar, bem como sobre os procedimentos realizados por cada órgão envolvido na investigação.

No município de Uberlândia, 87, 89 e $92 \%$ dos surtos notificados nos anos de 2014, 2015 e 2016, respectivamente, tiveram ações registradas pela equipe de fiscalização sanitária. Quando há a comunicação imediata de suspeitas de surtos de DTA's e os protocolos são cumpridos, os órgãos competentes têm a possibilidade de realizar as ações e elucidar as causas do surto de DTA's. A frequente comunicação entre os setores de vigilância sanitária e epidemiológica do munícipio e as unidades de saúde públicas e privadas, bem como a população acometida pelas DTA's, permitiria que a conclusão do surto, ou seja, a identificação do alimento suspeito e do agente etiológico, responsáveis por causar o surto de origem alimentar, fosse possível e teria impacto positivo na promoção de bem-estar e saúde para a população. 
Ação do profissional de saúde em surtos de DTA's em Uberlândia, Minas Gerais. Lombardi et al.

\section{CONCLUSÃO}

Foram constatadas falhas nos procedimentos realizados pelos médicos no atendimento de casos suspeitos de surtos de DTA's nos hospitais investigados. A implantação de uma ficha própria para cada paciente para suspeitas de DTA's e de preenchimento compulsório pelos médicos que atuam no pronto atendimento das unidades de saúde do município facilitaria a investigação de suspeitas de surtos.

Foi verificada que além desta falha, há um erro de comunicação entre os setores de investigação e unidades de saúde. Na maioria dos casos, as unidades não realizam a notificação, ou quando notificam, lançam dados incompletos (tipo de alimento, pacientes acometidos, dentre outras informações) dificultando a ações dos outros órgãos (vigilância epidemiológica e vigilância sanitária) na elucidação dos surtos. Devem ser realizadas capacitações permanentes dos profissionais de saúde nas unidades de pronto atendimento, em relação a suas responsabilidades nos procedimentos de investigação de doenças de origem alimentar para que tais falhas não ocorram.

\section{AGRADECIMENTO}

À FAPEMIG pelo apoio financeiro e à Vigilância Sanitária de Uberlândia pelo apoio técnico para a realização desta pesquisa.

\section{REFERÊNCIAS}

[1] Nunes M, Cergole-Novella MC, Tiba MT, Zanon CA, Bento ISS, Pashualinoto AL, Silva AA, Thomaz I, Walendy $\mathrm{CH}$. Surto de doença transmitida por alimentos nos municípios de Mauá e Ribeirão Pires - SP. Higiene Alimentar. 2017;31(264/265):97-102.

[2] Sirtoli DB, Camarella L. O papel da vigilância sanitária na prevenção das doenças transmitidas por alimentos (DTA). Revista Saúde e Desenvolvimento. 2018;12(10):197-209.

[3] Santos ACRB. Diagnóstico situacional da capacidade de resposta da rede hospitalar de emergência a eventos associados a viajantes internacionais em cidade - sede da Copa de 2014 - estudo de caso de Brasília. Rio de Janeiro: Fiocruz, 2013.
[4] Tonello IMS, Nunes RMS, Panaro AP. Prontuário do paciente: a questão de sigilo e a lei de acesso à informação. Revista Informação e Informação. 2013;18(2):193-210.

[5] Brasil.Ministério da Saúde.Secretaria de Vigilância em Saúde. Departamento de Vigilância Epidemiológica. Manual integrado de vigilância, prevenção e controle de doenças transmitidas por alimentos.Brasília: Editora do Ministério da Saúde,2010.

[6] Figueiredo MSD, Bisognin RP, Klein RL. Estudo do perfil epidemiológico dos surtos de doenças de transmissão hídrica e alimentar no Rio Grande do Sul: uma revisão dos registros no Estado. Revista Brasileira de Geografia Médica e da Saúde. 2017;13(25):48-64.

[7]Eckhardt F. Estudo do procedimento adotado no preparo de alimentos em restaurantes do município de Bento Gonçalves [trabalho e conclusão de curso]. Bento Gonçalves: Instituto Federal de Educação, Ciência e Tecnologia do Rio Grande do Sul, 2010.

[8] Brasil. Ministério da Saúde. Conselho Nacional de Saúde. Resolução no 466, de 12 de dezembro de 2012. Trata de pesquisas em seres humanos. Brasília: Diário Oficial da União, 13 dez 2012.

[9] CDC - Centro de Controle e Prevenção de Doenças. Surtos de Alimentos [internet]. 2017 [acesso em 16 mai 2017]. Disponível em: https://www.cdc.gov

[10] Silva Y. Doenças transmitidas por alimentos no município do Rio de Janeiro: Perfil Epidemiológico e Controle [dissertação]. Rio de Janeiro:Fundação Oswaldo Cruz, 2009.

[11] Oliveira JJ. Surtos Alimentares de Origem Bacteriana: uma revisão [dissertação].Goiânia: Universidade Federal de Goiás, 2012. 